\title{
Subjective perceptions of life among women after hysterectomy
}

\author{
Lubica Banovcinova* and Sona Jandurova \\ Comenius University in Bratislava, Slovakia
}

\begin{abstract}
Hysterectomy is the most commonly performed gynaecological surgery, which can influence woman's life in sexual, psychological, hormonal and social sphere. The aim of this study was to examine the subjective perceptions of life among women after hysterectomy (positive and negative effects of surgery, sources of social support, satisfaction with support, satisfaction with life and health). 70 women who underwent hysterectomy (mean age was $47.66 \pm 9.47 \mathrm{y} . ; 29-72$ ) were assigned for this study. The Multidimensional scale of perceived social support (MSPSS) and additional questions were used to gain information on social support, positive and negative effects of surgery, satisfaction with support, satisfaction with life and health. The majority $(68.6 \%)$ of respondents prefer husband or partner as a source of support and were subjectively satisfied with this support (81.4\%). 20\% sought support outside family and friends network and priest, psychologist and support groups were their preferred supporters. The most cited positive aspects of hysterectomy were the disappearance of symptoms and reduced fear of uterine cancer. Most women did not see any negative consequences of surgery $(45.7 \%)$ and were subjectively satisfied with their life (90\%). Since the social support is one of the important factors affecting women's life, healthcare professionals should also focus on building and strengthening patient's support network when working with these groups of women.
\end{abstract}

Key words: hysterectomy, gynaecological surgery, negative effects, subjective perceptions of life.

\section{Introduction}

Quality of life is an important outcome variable in clinical research as medical interventions can affect it in both positive and negative ways [1]. Health-related QoL is a multidimensional concept, which encompasses physical, emotional and social aspects associated with a given disease or its treatment [2]. Hysterectomy is the most commonly performed gynaecological surgery, which results in sterility, absence of menstruation and consequences in sexual, psychological, hormonal and social sphere.

Many women receive hysterectomy due to nonmalignant symptoms such as menstrual pain, menorrhagia, unexplained uterine bleeding and chronic pelvic pain, which have an adverse effect on a woman's quality of life. Most women reported a reduction in physical symptoms and pain and an increase in health perceptions and quality of life after hysterectomy [2].

\footnotetext{
* Corresponding author: banovcinova@jfmed.uniba.sk
} 
Other positive outcomes relate to the cessation of abnormal uterine bleeding and relief from monthly menstrual symptoms, pelvic pain caused by endometriosis, pressure symptoms associated with fibroids, urinary incontinence, sexual function, and depression and anxiety [3]. In symptomatic women with menstrual or related disorders where conservative treatment has failed, total or subtotal hysterectomy may improve quality of life and reduce psychiatric symptoms, with both procedures having an equally beneficial effect $[1,4]$.

However, hysterectomy may also result in the development of new problems such as pelvic/ abdominal pain, urinary problems, constipation, weight gain, fatigue, lack of interest or enjoyment in sex, depression, anxiety and negative feelings about oneself as a woman [2]. Concerns also include loss of childbearing capacity, change in self-image, social and domestic disruptions, long recovery times, and wound pain up to a year after surgery [3].

It represents very stressful event, as it involves the loss of body parts associated with womanhood and femininity, causing significant changes in women's bodies [5, 6]. Femininity has been proposed as a positively valued quality, thus, the perception of losing one's femininity is a serious and threatening event in a woman's life [2]. Hysterectomy leave women burdened by infertility, negative body image, and feeling flawed as a woman and sexually undesirable. Unfortunately, these concerns are rarely voiced and addressed, as patients often feel uncomfortable and embarrassed [7].

Ashing-Giwa et al. [7] describes a hysterectomy-related stigma on womanhood as well as single women's difficulty in dating. Concerns about loss of fertility [8], femininity and related psychological problems are common also among women treated for gynaecological cancer. Numerous factors may contribute to the surrounding emotional turmoil as women are required to make treatment choices for survival that negatively impact on fertility and childbearing decisions [8]. Factors that have been identified to increase the risk of postoperative psychological problems include young age at time of surgery, lower socioeconomic status, educational level, poor social support and pessimism, etc. Research suggests that age may be particularly relevant in psychological distress after hysterectomy, showing that younger women (under 50 years old) tend to have better physical functioning than older women but worse emotional wellbeing and quality of life [5]. Cooper et al. [8] suggest that women who undergo hysterectomy at a young age are a defined group who may require more support than other women to maintain good psychological health in middle age. On the other hand, social support and emotional wellbeing are often affected by debilitating symptoms as well as hysterectomy [9].

The purposes of this study were as follows: 1) to investigate the subjective perceptions of life among women after hysterectomy (positive and negative effects of surgery, satisfaction with life and health); 2) to explore women's sources of social support and their satisfaction with support; 3) to investigate whether perceived social support influences women's health outcomes.

\section{Methods}

Seventy women who underwent hysterectomy, between the ages of 29 and 72 were assigned for this study. Women underwent surgery for a variety of reasons, including myoma, endometriosis, cancer, menorrhagia/dysfunctional uterine bleeding, urinary incontinence, complications during labour, and chronic pelvic pain syndromes. The questionnaire was filled out only by women having hysterectomy regardless of length of time elapsed since surgery, indication and age. Respondents were between the ages of 29 and 72 . The average age of the respondents was 47.66 and the mean age at the time of surgery was 43.31 .

The selection of the participants was intentional: the operative procedure - hysterectomy was the basic criterion for inclusion in the research sample. 
In data collection, we employed two questionnaires supplemented by additional questions.

Short Form 36 Health Subject Questionnaire (SF 36) is a frequently used tool for assessing the quality of life in various medical branches because of its good reporting value. It evaluates 8 basic dimensions that affect the quality of life. In addition, question 1 can be converted into "self-rated health" and question 2 into "changes in health" scores. SF-36 consists of eight subscales: bodily pain, physical functioning, physical role limitations, general health perceptions, vitality, emotional role limitations, mental health and social functioning. Subscale score and SF-36 questionnaire components are in the range of 0-100, the higher value means better perceived health status.

The perceived social support was measured by the Multidimensional questionnaire of perceived social support by Zimet, Dahlem and Farley. The questionnaire is composed of 12 items in which respondents assess whether they are provided with the necessary help and support from the family, friends and important persons in their personal life on the 7 point scale from "Definitely Disagree" to "Definitely Agree". The evaluation allows three groups of social support resources to be identified: the family (items 3, 4, 8 and 11), friends $(6,7,9$ and 12) and another significant person in life (items 1, 2, 5 and 10). The values of the items are added separately. The highest score means a higher degree of perceived social support [10].

Additional question was used to gain information on positive and negative effects of surgery and satisfaction with support.

\section{Results}

Baseline characteristics and clinical variables are summarised in Table 1. The main age of respondents was 47.66 and mean age during surgery 43.31 years. Majority of respondents were married (77\%), had at least a high school education (80\%) and had 1-2 children (61.44).

To investigate the subjective perceptions of life among women after hysterectomy (positive and negative effects of surgery), we formulated two open questions. The summary of the most frequented answers is presented in Figs. 1 and 2.

In this question, up to $45.71 \%$ of women answered that they did not see any negative consequences, $21.43 \%$ of women considered the negative effects of hormonal changes (symptoms of menopause), $15.71 \%$ of respondents labelled the loss of fertility. One respondent wrote that for her the biggest negative was the long-term drop out of work and, in particular, of the condition, a major weakening of the body.

The most commonly cited positive aspect of hysterectomy was that $42.86 \%$ reduction/ elimination of disease-related problems, reduced fear of endometrial cancer (27.14\%) and "other" where respondents wrote, e.g. that they save on contraceptives and sanitary napkins, have a longer and more precise orgasm, pain relief.

Table 2 presents results from generic questionnaire of quality of life SF 36. Respondents reached the highest average score in physical functioning subscale, while the worst results were achieved in subscales vitality and bodily pain.

Most respondents evaluated their health as "good" (58.57\%) or "very good" $(27.14 \%)$, only 3 women $(4.29 \%)$ rated their health as "bad".

On Fig. 3, we can see that $40 \%$ of women evaluated their health approximately the same as before surgery, and up to $27.14 \%$ felt much better or somewhat better $(15.71 \%)$ than before surgery. $15.71 \%$ of respondents felt somewhat worse and $1.43 \%$ much worse than before hysterectomy. 
Table 1. Sample characteristics.

\begin{tabular}{|l|c|}
\hline & Frequency n(\%) \\
\hline Age (mean \pm SD) & $47.66 \pm 9.47$ \\
\hline Age during surgery (mean \pm SD) & $43.31 \pm 9.12$ \\
\hline Education & \\
\hline$<$ High school diploma & $14(20)$ \\
\hline High school diploma & $40(57.14)$ \\
\hline University degree & $16(22.86)$ \\
\hline Marital status & \\
\hline Married/with partner & $54(77.14)$ \\
\hline Not married/widowed & $16(22.86)$ \\
\hline Parity & \\
\hline Nulipara & $4(5.71)$ \\
\hline $1-2$ children & $43(61.44)$ \\
\hline $3-4$ children & $23(32.85)$ \\
\hline Indication for surgery & \\
\hline Myoma & $37(53)$ \\
\hline Endometriosis & $5(9)$ \\
\hline Menorrhagia & $3(4)$ \\
\hline Complications during labour & $4(6)$ \\
\hline Cancer & $8(11)$ \\
\hline Other & $12(17)$ \\
\hline Type of surgery & \\
\hline Abdominal hysterectomy & $49(70)$ \\
\hline Laparoscopic/vaginal hysterectomy & $19(27.14)$ \\
\hline Unknown & $2(2.86)$ \\
\hline Would have wanted a (another) child & \\
\hline Yes & $14(20)$ \\
\hline No & $56(80)$ \\
\hline
\end{tabular}

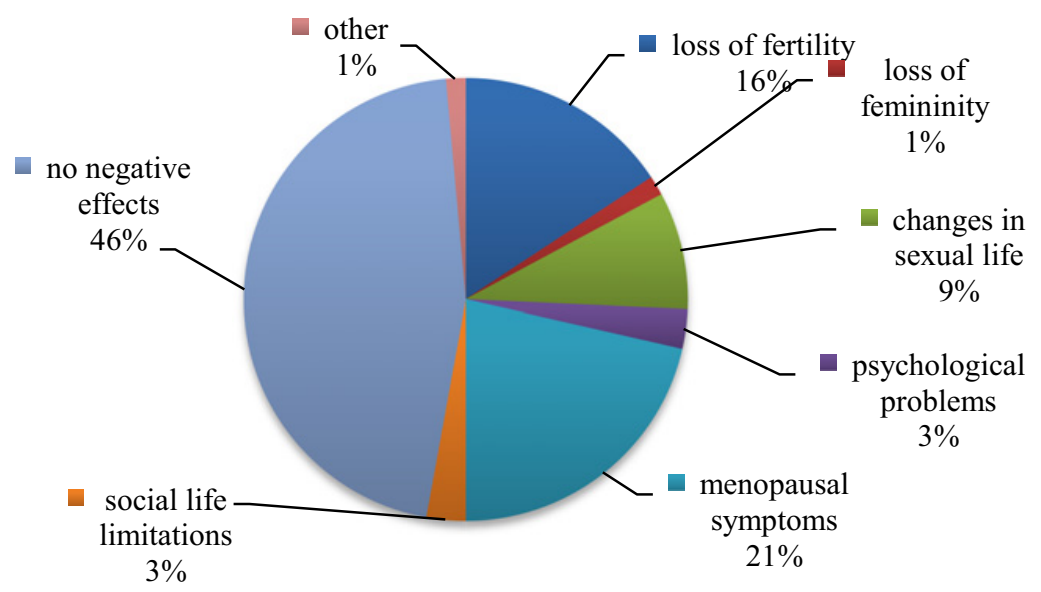

Fig. 1. What do you consider to be the most negative aspect of hysterectomy?

When analyzing the differences between two groups by desire for a (another) child, a significant difference was found only in mental health. The women who answered "yes" in response to the question, "Before the hysterectomy, would you have wanted a (another) child?", achieved a lower score in mental health subscale than those who said "no", as shown in Table 3. 


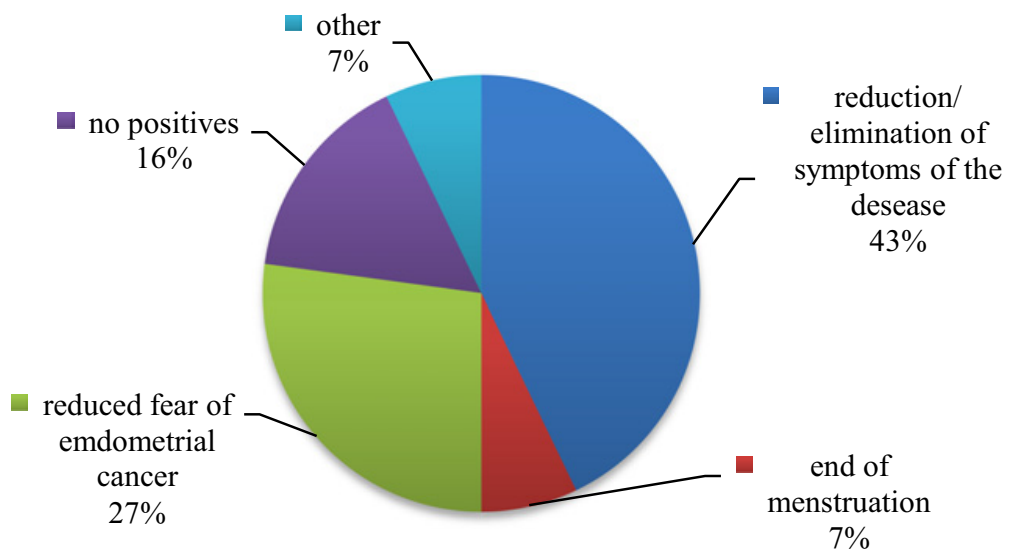

Fig. 2. What do you consider the most positive aspect of hysterectomy?

Table 2. Average values of each quality of life dimension according to the SF-36 questionnaire.

\begin{tabular}{|l|c|c|c|c|}
\hline & Mean & SD & \multicolumn{2}{|c|}{ Range } \\
\hline Physical functioning & 88.07 & 12.67 & 45 & 100 \\
\hline Social functioning & 74.64 & 22.81 & 12.5 & 100 \\
\hline Role limitations due to physical health problems & 70.36 & 34.65 & 0 & 100 \\
\hline Role limitations due to emotional health problems & 75.24 & 33.42 & 0 & 100 \\
\hline Mental health & 67.43 & 13.89 & 28 & 88 \\
\hline Vitality, energy, fatigue & 52.07 & 15.68 & 5.0 & 90 \\
\hline Bodily pain & 44.14 & 24.57 & 0 & 100 \\
\hline General health & 63.79 & 17.80 & 20 & 100 \\
\hline Changes in health & 62.50 & 27.83 & 0 & 100 \\
\hline Physical health & 69.63 & 11.76 & 41.11 & 95.19 \\
\hline Mental health & 63.39 & 12.61 & 28.57 & 91.07 \\
\hline Self-rated health & 61.79 & 21.33 & 0 & 100 \\
\hline
\end{tabular}

When comparing the impact of different types of hysterectomy on individual quality of life dimensions, we found a statistically significant difference in the pain and role limitations due to emotional problems. Respondents, who underwent abdominal hysterectomy tend to achieve worse mean scores in both dimensions.

As shown in Table 5, no significant difference in quality of life results was found among groups of respondents according to the performed oophorectomy.

The Multidimensional scale of perceived social support was used to explore women's sources of social support and their satisfaction with support. The questionnaire allows you to specify 3 groups of resources (family, friends, other significant person).

Social support from family and significant others were perceived in equal amounts (mean 23.37 and $24.66 ; \mathrm{SD}=4.11 ; 3.48$ respectively). Slightly lower scores were achieved by respondents in subscale of perceived social support from friends (mean 22.07; $\mathrm{SD}=4.21$ ). 


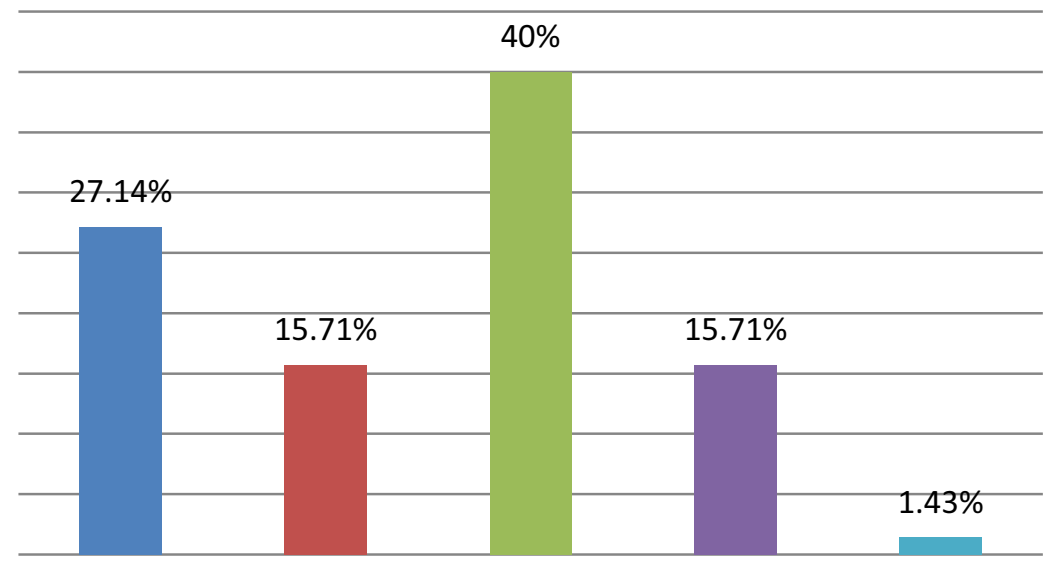

Fig. 3. How would you rate your health today compared to before surgery?

To a standardized questionnaire about perceived social support, we even added an open question about who respondents considered the greatest source of social support. As expected the most commonly cited source of support was husband/partner $(68.7 \%)$, followed by children $(12.86 \%)$ and female family member $(8.57 \%)$. Only 14 women sought support outside their normal social network, with priest, psychologist and support groups being the most cited $(35.72 \% ; 21.43 \%$, respectively).

Spearman correlation analysis was performed between quality of life domains, and the total and three subscales of social support (Table 7) to investigate whether perceived social support influence women's health outcomes.

Positive correlation was found between total social support and family and friends subscale, and mental health components $(p<0.05)$. Perceived social support from family was also significantly associated with vitality dimension $(p<0.05)$ as well as self-rated health $(p<0.05)$.

\section{Discussion}

Respondent's mean age was $47.66 \pm 9.47$ years. The majority were less than 50 years old, were employed, had secondary education level, were living with husband/partner. Most of them prefer husband or partner as a source of support and were subjectively satisfied with support from husband/partner and only one fifth sought support outside family and friends network and priest, psychologist and support groups were their preferred supporters.

The aim of our research was to explore the perception of women who for various reasons in the past underwent hysterectomy. The results show that most women are satisfied with the outcome of the surgery and do not see any negative consequences. In contrast, most women reported a positive reduction in symptoms and disease-related problems and assessed their health better than before surgery. These results coincide with the findings of several authors. Satisfaction with hysterectomy has consistently been reported as being high among women who undergo hysterectomy $[3,11,12]$. However, hysterectomy may sometimes result in new symptoms related to pain, sexual dysfunction, and psychological distress [12, 13]. In our study, some women see the symptoms of menopause and loss of fertility as limiting.

When analyzing the differences between two groups by desire for a (another) child, a significant difference was found in mental health. The women, who would have wanted another child, achieved a lower score in mental health subscale. Loss of fertility is particularly 
Table 3. Post-hysterectomy quality of life by desire for a (another) child $(N=70)$.

\begin{tabular}{|c|c|c|c|c|c|}
\hline & $\begin{array}{l}\text { Would have } \\
\text { wanted a } \\
\text { (another) } \\
\text { child }\end{array}$ & $N$ & MR & $\mathbf{U}$ & $p$ \\
\hline \multirow{2}{*}{ Physical functioning } & yes & 14 & 33.11 & \multirow{2}{*}{358.500} & \multirow{2}{*}{.616} \\
\hline & no & 56 & 36.10 & & \\
\hline \multirow{2}{*}{ Social functioning } & yes & 14 & 30.25 & \multirow{2}{*}{318.500} & \multirow{2}{*}{.27} \\
\hline & no & 56 & 36.81 & & \\
\hline \multirow{2}{*}{$\begin{array}{l}\text { Role limitations due to } \\
\text { physical health problems }\end{array}$} & yes & 14 & 41.71 & \multirow[t]{2}{*}{305.000} & \multirow[t]{2}{*}{.174} \\
\hline & no & 56 & 33.95 & & \\
\hline \multirow{2}{*}{$\begin{array}{l}\text { Role limitations due to } \\
\text { emotional health problems }\end{array}$} & yes & 14 & 34.93 & \multirow[t]{2}{*}{384.000} & \multirow[t]{2}{*}{.896} \\
\hline & no & 56 & 35.64 & & \\
\hline \multirow{2}{*}{ General mental health } & yes & 14 & 22.71 & \multirow{2}{*}{213.000} & \multirow{2}{*}{.008} \\
\hline & no & 56 & 38.70 & & \\
\hline \multirow{2}{*}{ Vitality, energy, fatigue } & yes & 14 & 29.43 & \multirow{2}{*}{307.000} & \multirow{2}{*}{.207} \\
\hline & no & 56 & 37.02 & & \\
\hline \multirow{2}{*}{ Bodily pain } & yes & 14 & 36.39 & \multirow{2}{*}{379.500} & \multirow{2}{*}{.853} \\
\hline & no & 56 & 35.28 & & \\
\hline \multirow{2}{*}{ General health } & yes & 14 & 33.36 & \multirow{2}{*}{362.000} & \multirow{2}{*}{.658} \\
\hline & no & 56 & 36.04 & & \\
\hline \multirow{2}{*}{ Physical health } & yes & 14 & 35.18 & \multirow{2}{*}{387.500} & \multirow{2}{*}{.947} \\
\hline & no & 56 & 35.58 & & \\
\hline \multirow{2}{*}{ Mental health } & yes & 14 & 25.57 & \multirow{2}{*}{253.000} & \multirow{2}{*}{.041} \\
\hline & no & 56 & 37.98 & & \\
\hline \multirow{2}{*}{ Self-rated health } & yes & 14 & 37.04 & \multirow{2}{*}{370.500} & \multirow{2}{*}{.721} \\
\hline & no & 56 & 35.12 & & \\
\hline
\end{tabular}

MR-mean rank; U-Mann-Whitney test.

distressing for women who had not yet had children and younger women [7, 14]. Some women who have undergone hysterectomy do not achieve their desired family size and report regret at the loss of fertility $[3,5,14]$. Such feelings of regret and distress at the loss of fertility are often cited as a potential explanation of the association between hysterectomy and subsequent psychological health $[3,15]$.

When comparing the impact of different types of hysterectomy on individual quality of life dimensions, we found that respondents, who underwent abdominal hysterectomy tent to achieve worse scores in the pain and role limitations due to emotional problems. A prospective controlled study found that approximately $90 \%$ of women felt physically unattractive because of the scars following abdominal hysterectomy, and that $25 \%$ of patients would not elect to undergo an abdominal hysterectomy again versus $11 \%$ in the vaginal 
Table 4. Quality of life by type of hysterectomy.

\begin{tabular}{|l|c|c|c|c|c|}
\hline & \multicolumn{2}{|c|}{$\begin{array}{c}\text { Abdominal } \\
\text { hysterectomy }\end{array}$} & \multicolumn{2}{c|}{$\begin{array}{c}\text { Laparoscopic/ } \\
\text { Vaginal hysterectomy }\end{array}$} & $p$ \\
\hline$N=70$ & \multicolumn{2}{|c|}{$N=49$} & \multicolumn{2}{|c|}{$N=19$} & \\
\hline & $\mathrm{M}$ & $\mathrm{SD}$ & $\mathrm{M}$ & $\mathrm{SD}$ & \\
\hline Physical functioning & 87.6 & 12.70 & 88.68 & 15.26 & .443 \\
\hline Social functioning & 72.45 & 24.08 & 80.26 & 19.24 & .276 \\
\hline $\begin{array}{l}\text { Role limitations due to } \\
\text { physical health problems }\end{array}$ & 68.37 & 33.80 & 77.63 & 33.22 & .253 \\
\hline $\begin{array}{l}\text { Role limitations due to } \\
\text { emotional health problems }\end{array}$ & 70.04 & 33.84 & 87.71 & 25.36 & $\mathbf{. 0 4 1}$ \\
\hline Mental health & 62.14 & 16.81 & 66.53 & 12.02 & .587 \\
\hline Vitality, energy, fatigue & 51.22 & 17.77 & 54.21 & 10.84 & .516 \\
\hline Bodily pain & 41.27 & 24.02 & 58.79 & 25.14 & $\mathbf{. 0 0 4}$ \\
\hline General health & 62.14 & 16.81 & 62.37 & 20.57 & .752 \\
\hline
\end{tabular}

Table 5. The influence of oophorectomy on the quality of life dimension.

\begin{tabular}{|l|c|c|c|c|c|c|c|}
\hline & \multicolumn{2}{|l|}{$\begin{array}{l}\text { Bilateral } \\
\text { oophorectomy }\end{array}$} & \multicolumn{2}{l|}{$\begin{array}{l}\text { Unilateral } \\
\text { oophorectomy }\end{array}$} & \multicolumn{2}{l|}{$\begin{array}{l}\text { Without } \\
\text { oophorectomy }\end{array}$} & \\
\hline \multicolumn{1}{|c|}{$N=70$} & \multicolumn{2}{|c|}{$N=29$} & \multicolumn{2}{|c|}{$N=8$} & \multicolumn{2}{|c|}{$N=33$} & $p$ \\
\hline & $\mathrm{M}$ & $\mathrm{SD}$ & $\mathrm{M}$ & $\mathrm{SD}$ & $\mathrm{M}$ & $\mathrm{SD}$ & \\
\hline Physical functioning & 86.90 & 12.55 & 82.50 & 18.20 & 90.45 & 11.70 & .205 \\
\hline Social functioning & 72.41 & 22.11 & 82.81 & 29.27 & 75.00 & 21.09 & .249 \\
\hline $\begin{array}{l}\text { Role limitations due to } \\
\text { physical health problems }\end{array}$ & 68.10 & 34.05 & 71.88 & 38.40 & 75.00 & 31.38 & .611 \\
\hline $\begin{array}{l}\text { Role limitations due to } \\
\text { emotional health problems }\end{array}$ & 70.09 & 35.39 & 83.31 & 23.60 & 75.74 & 33.11 & .507 \\
\hline Mental health & 60.34 & 16.24 & 63.75 & 21.18 & 61.67 & 17.65 & .834 \\
\hline Vitality. energy. fatigue & 54.14 & 12.74 & 48.75 & 18.99 & 52.88 & 17.63 & .863 \\
\hline Bodily pain & 46.55 & 21.65 & 35.63 & 23.18 & 50.33 & 28.11 & .293 \\
\hline General health & 60.34 & 16.24 & 63.75 & 21.18 & 61.67 & 17.65 & .662 \\
\hline
\end{tabular}

M-mean; SD-standard deviation.

group [16]. Tan et al. [9] present data showing that in patients with debilitating symptoms, particularly pain, total abdominal hysterectomy and bilateral salpingo-oophorectomy result in significant improvement in health-related quality of life (HRQoL). Radosa et al. [17] state that hysterectomy, performed due to benign uterine pathologies, had significant positive effects on postoperative sexual function and quality of life, regardless of the surgical technique used.

One of the factors closely related to the quality of life is social support. Positive support has been shown to enhance self-esteem, confidence, and coping ability; conversely, negative support makes coping more difficult by eroding these perceptions $[18,19]$. In our study, social 
Table 6. Multidimensional scale of perceived social support.

\begin{tabular}{|l|l|l|l|}
\hline & Mean & SD & Range \\
\hline Social support - Family & 23.37 & 4.11 & $12-28$ \\
\hline Social support - Friends & 22.07 & 4.21 & $10-28$ \\
\hline Social support - Significant others & 24.66 & 3.48 & $11-28$ \\
\hline
\end{tabular}

Table 7. Spearman correlation between dimensions of quality of life and sources of social support.

\begin{tabular}{|c|c|c|c|c|}
\hline & \multicolumn{4}{|c|}{ Perceived social support } \\
\hline & family & friends & significant others & total \\
\hline Physical functioning & .136 & .186 & .146 & .177 \\
\hline Social functioning & -.058 & .087. & .071 & .036 \\
\hline $\begin{array}{l}\text { Role limitations due to } \\
\text { physical health problems }\end{array}$ & -.039 & -.097 & -.131 & -.098 \\
\hline $\begin{array}{l}\text { Role limitations due to } \\
\text { emotional health problems }\end{array}$ & .015 & -.028 & -.016 & -.011 \\
\hline Mental health & $.263 *$ & $.278 *$ & .155 & $.267 *$ \\
\hline Vitality, energy, fatigue & $.280 *$ & .183 & .127 & .226 \\
\hline Bodily pain & -.007 & .099 & -.017 & .032 \\
\hline General health & .209 & .199 & .147 & .211 \\
\hline Physical health & .184 & .092 & .105 & .180 \\
\hline Mental health & $.248 *$ & $.237 *$ & .149 & $.240 *$ \\
\hline Self-rated health & $.255 *$ & .157 & .134 & .208 \\
\hline
\end{tabular}

* Correlation is significant at the 0.05 level (2-tailed).

support was perceived by respondents in equal amounts from all three sources (family, friends and significant others). Study carried out by Cabness [20] found that women have reported greater interaction with family and friends after hysterectomies because of an increased desire for socialization and improved energy levels.

Positive correlation was found between social support and mental health components. Perceived social support from family was also significantly associated with vitality dimension as well as self-rated health. According to Gomez-Campelo et al. [5] social support has been widely acknowledged as a protective factor for psychological distress and mental well-being and lower levels of social support have been associated with high levels of depression, and the lower support received can contribute to increased psychological problems for women.

Despite the many positive results of the surgery, a number of physical, psychological and social problems arise after hysterectomy. In order to help women to minimize deficits, we need to know which aspects of quality of life are most markedly disrupted [21]. In situations in which hysterectomy is the only medically indicated treatment or a last resort treatment after other treatments have failed, clinicians must be aware of the association between loss of fertility and psychological distress in some women, especially younger women and nulliparous women [14]. 


\section{Conclusions}

The main aim of our study was to examine the subjective perceptions of life among women after hysterectomy. It was found that, despite some negative effects, women perceive their life after the surgery positively. They were also satisfied with support mainly from husband/partner and their children. Since the social support is one of the important factors affecting women's good recovery and mental health after surgery as well as their quality of life, healthcare professionals should also focus on building and strengthening patient's support network when working with these groups of women.

\section{References}

[1] R. Thakar, S. Ayers, A. Georgakapolou, P. Clarkson, S. Stanton, I. Manyonda, BJOG 111 (2004)

[2] Y.L. Yang, Y.C.H. Chen, Y.M. Chao, G. Yao, J. Fermosan Med. Assoc. 105, 9 (2006)

[3] C.M. Farquhar, S.A. Harvey, Y. Yu, L. Sadler, A.W. Stewart, Am. J. Obstet. Gynecol. 194 (2006)

[4] J. Chandana, G. Asanka, G. Champika, et al., J. Gynecol. Reprod. Med. 1, 3 (2017)

[5] C. Goméz-Campelo, M.J. Bragado-Álvarez, Hernández-Lloreda, Psycho-Oncol. 23 (2014)

[6] N. Reis, N. Kizilkaya Beji, A. Coskun, Eur. J. Oncol. Nursing 14 (2010)

[7] K.T. Ashing-Giwa, M. Kagawa-Singer, G.V. Padilla, J.S. Tejero, E. Hsiao, R. Chhabra et al., Psychooncol. 13 (2004)

[8] J. Carter, Y. Sonoda, N.R. Abu-Rustum, Gynecol. Oncol. 105, 1 (2007)

[9] B.K. Tan, K. Maillou, R.S. Mathur, A. Prentice, Eur. J. Obstet. \& Gynecol. Reprod. Biol. 170 (2013)

[10] I. Nagyova (ed.), Measuring health and quality of live in the chronically ill (EQUILIBRIA Ltd, Kosice, 2009)

[11] G. Khastgir, J. Studd, Am. J. Obstet. Gynecol. 183, 6 (2000)

[12] N. Flory, F.T. Bissonnette, Y.M. Binik, J. Psychosomatic Res. 59 (2005)

[13] M.L. Reitsma, E.G. Vandenkerkhof, S.L. Johnston, W.M. Hopman, J. Obstet. Gynaecol. Can. 33 (2011)

[14] P.C. Leppert, R.S. Legro, K.H. Kjerulff, J. Psychosomatic Res. 63 (2007)

[15] R. Cooper, G. Mishra, R. Hardy, D. Kuh, J. Affective Disord. 115 (2009)

[16] P. Gutl, E.R. Greimel, R. Roth, R. Winter, J. Psychosomatic Obstet. Gynaecol. 23, 1 (2002)

[17] J.C. Radosa, G. Meyberg-Solomayer, C. Kastl, C.G. Radosa, R. Mavrova, S. Gräber, S. Baum, M.P. Radosa, J. Sex Med. 11 (2014)

[18] S.M. Cohen, A.O. Hollingsworth, M. Rubin, B.M. Graff, J.S. Thomas, H.K. Welz, L.E. Wehry, WebmedCentral Obst. Gynaecol. 2, 3 (2011)

[19] S.M. Cohen, H.K. Linenberger, L.E. Wehry, H.K. Welz, WebmedCentral Obstet. Gynaecol. 2, 3 (2012)

[20] J. Cabness, Social Work in Health Care 49 (2010)

[21] E. Krištofová, M. Boledovičová, I. Macáková, Život žien po hysterektómii. KONTAKT. 13, 2 (2011) 